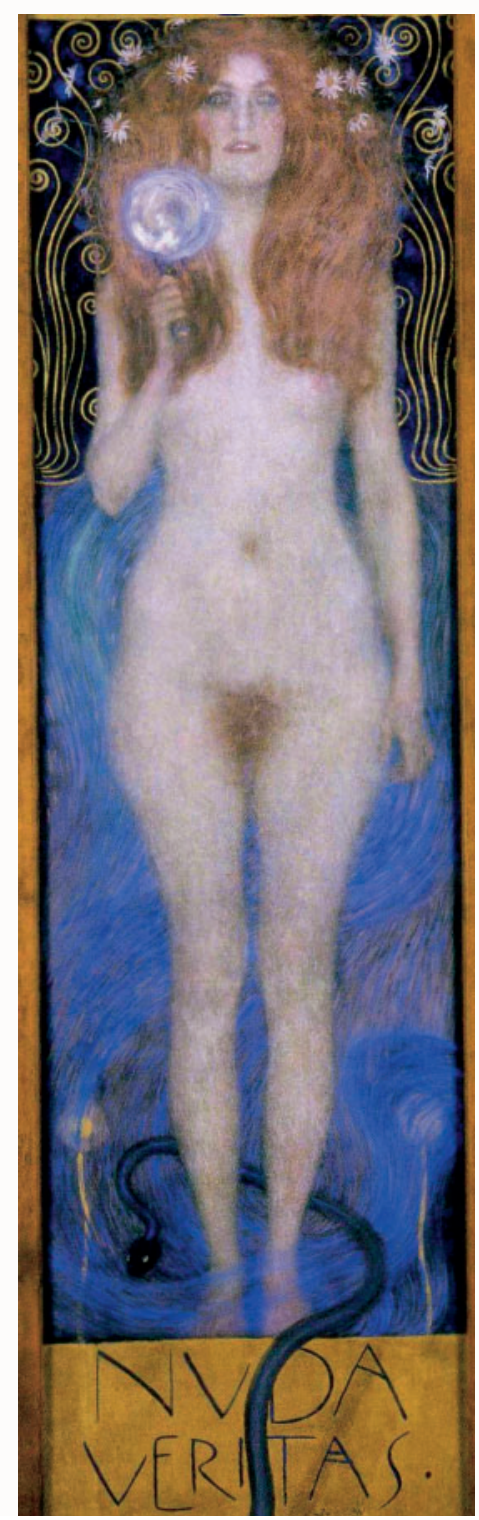

\section{Die nackte Wahrheit}

Früher, als es noch Grenzen gab, war es schön, mit U. vor die Staatsgewalt zu treten und zuzusehen, wie sie den Pullover hochzog und den Brustbeutel aus dem Intimversteck zerrte. In der Regel war der hoheitliche Akt damit erledigt und der Zöllner offensichtlich erleichtert, dass es zur Ausschälung der Kennkarte keiner weiteren Entblößungen bedurfte. Europa hat uns um manche Erfahrung ärmer gemacht. Und das völlige Verschwinden des Brustbeu-

Zum Autor: Hans-Joachim Müller

- Studium der Philosophie und

Kunstgeschichte in Freiburg i. Br.

- langjähriger Mitarbeiter im

Feuilleton der ZEIT

- zuletzt Feuilletonchef und

Mitglied der Redaktionsleitung

der Basler Zeitung

- lebt heute als freier Autor

(FAZ, ZEIT, NZZ, art-Magazin) in

Freiburg und in Süditalien. tels darf einen auch etwas wehmütig stimmen. Jetzt, wo die Pullover so kurz geschnitten sind, machte die hängende Aufbewahrung der Effekten gar keinen Sinn mehr. Wie sähe es auch aus, wenn das Futteral unter der Oberkleidung vorschaute und bei jedem Schritt auf den Nabel klatschte.

Vielleicht war es ja auch der etwas schwergewichtig sackartige Mitklang, der Begriff und Sache ganz aus der Mode kommen ließ. Man hat es eben doch gern etwas leichter, formstabiler. Abgesehen davon, dass es schon immer etwas anrüchig war, Geldscheine im Mieder zu verstecken. Wie auch immer, der nackte Jungbauch hat die Aufmerksamkeit von Brust und Beutel abgezogen, das ist die Wahrheit. Und wahrer als die nackte Wahrheit kann die Wahrheit schlechterdings nicht sein.

Eine ganze Sprachepoche lang dachte sich niemand etwas dabei, wenn die beklagenswerte Wahrheit im Idealfall überhaupt nichts anhaben und völlig bloß in der Öffentlichkeit herumstehen sollte. Woher die strenge Kleidervorschrift rührte, ist nie zufrieden stellend geklärt worden. So wenig, wie es am exklusiv weiblichen Geschlecht der Wahrheit je einen Zweifel gegeben hat. Den nackten Wahrheitsmann, den sucht man in der Symbolgeschichte vergebens. Es mag bedauerlich sein, dass man inm weder Nacktheit noch Wahrheit zutraut, aber es hat den Mann auch gnädig davor bewahrt, völlig bloß in der Öffentlichkeit herumstehen zu müssen.

Was ja auch Frau Wahrheit nicht so freiwillig tut. Wahrheit kommt nicht einfach an den Tag, wie man meinen möchte. Ein bisschen gnädige Verhüllung, Verschleierung ein wenig Design um die peinlichen Tatsachen, dagegen hat die Wahrheit keine triftigen Einwände. Und bekömmlich ist sie meist nur in kleinen Portionen. So auf einen Schlag, so vollends nackt erscheint sie eher als Zumutung. Und wenn man doch noch einmal von der "nackten Wahrheit" spricht, was kaum einer mehr tut, dann droht man auch auf eine Weise mit ihr, stellt etwas in Aussicht, was so ganz geheuer nicht ist. Denn Nacktheit meint verratenes Geheimnis. Wenn die Wahrheit nackt, wenn Frau Wahrheit nackt ist, dann ist ihr Bild an seinem Verratsziel angekommen. Zum Verrat aber gehören zwei, ein Verräter und eine Verratene. Nie zieht sich die Wahrheit selber aus. Immer lässt sie sich enthüllen, Stück um Stück, wie der Körper enthüllt wird - mit den Augen, die so lange auf inn schauen, bis er nackt ist. Selten einmal sind die Bilder der Nacktheit anders überliefert als in der Formel männlicher Enthüllungsarbeit am weiblichen Wahrheitskörper. 
Das ist nicht ohne Delikatesse. Weshalb man auch den Zoll vom Dienst an Brust und Beutel abberufen und die Kernkompetenz in Sachen Nacktheit ganz auf Arzt und Maler übertragen hat. Der eine schafft mit Ultraschall, der andere mit Acrylfarbe. Beide schaffen sie im Namen der Wahrheit. Und beide sind sie diplomiert für die berufsmäßige Begegnung zwischen einem bekleideten Mann und einer unbekleideten Frau. Wobei wir über die Abläufe in der Praxis wesentlich besser unterrichtet sind als über die $\mathrm{Zu}$ stände im Atelier. Was dort zu geschehen pflegt, weiß niemand so genau. Es gibt literarische Berichte vom Künstler in seinem Studio, aber sie sind so durchwirkt mit Phantasien, dass auf sie wenig Verlass ist. Das Atelier ist ein mythischer Ort, ein Bühnenort des Wunders, ein Ort, an dem die populäre Vorstellung alle Rätsel bewahrt wähnt, die das aufgeklärte Leben verloren hat. Und ausgerechnet dort, wo die magischen Bilder geboren werden, ausgerechnet dort soll es mit der Wahrheit zugehen, mit der nackten zumal?

Beim Maler Gustav Klimt hält die aparte Wahrheitsfrau - Nuda Veritas, wie sie in der Szene heißt einen Spiegel in der Hand, in dem sie sich eigentlich wohlgefällig zu betrachten hat, den sie aber uns entgegenstreckt - wie um uns ein wenig zu blenden. Es ist heikel, der nackten Wahrheit ins Gesicht oder sonst wohin zu sehen. Und wir können doch nicht lassen davon.

Alles wissen wir von der Nacktheit. Wir kennen sie an uns, und wir kennen sie am anderen Körper. Und wir wissen doch nie genug von ihr. Nacktheit ist, was sich auf seltsame Weise der Gewöhnung entzieht, was resistent bleibt gegen seine Vernutzung im Bild. Wir können noch so lückenlos umgeben sein mit Bildern der Nacktheit, angesichts des nackten Körpers ist es dann doch wieder, als sei er niemals Bild geworden. Lassen wir den Maler also beteuern, allein der Wahrheit auf den Grund gehen, nur die Natur der Dinge und der Körper studieren zu wollen. Kein fleißiges Studium bewahrt davor, dass sich im Körperbild der Nacktheit unversehens der Wahrheitswunsch mit dem Begehrenswunsch verbündet. Und wir brauchen uns nicht zu wundern, wenn all die ungezählten Bilder der Nacktheit viel weniger von der Wahrheit als von der Nacktheit handeln, also vom Schauen, vom Hinschauen und vom Wegschauen, von der erträglichen und der unerträglichen Nähe der Körper, vom Überdruck an Intimität im Menschenversuchslabor Atelier.

Es ist wie eine ikonografische Zwangshandlung. Immer hat der bekleidete Maler die unbekleidete Frau malen wollen. Ein Ostinato der Nacktheit, das die Bildgeschichte von ihren Anfängen an durchzieht. Und mehr noch: ein Privileg, das sich die Kunst wer weiß wie erworben hat. Sie darf mit Nacktheit umgehen, wie der Apotheker mit Drogen umgehen darf, die dem Nicht-Apotheker verboten sind. Also mischt der Maler die nicht ungefährlichen Ingredienzien ganz nach seinem Vermögen, erwischt die Frau mal beim Baden, mal im Bad, in schicklichen Schamrollen und riskanter Akrobatik. Liegend, stehend, kauernd, ganz nackt, halbnackt und immer eine keusche Brust darbringend. Es gibt die Kümmerformen der Nacktheit und die Hochleistungsnacktheit. Nacktheit gibt es in allen vorstellbaren Varianten, und es ist ziemlich unerheblich, ob Eva, Venus, Frühling, Wahrheit oder Sünde ein feines Tüchlein um die Lenden gewunden haben oder nicht, anders als brustfrei traten sie niemals in der Öffentlichkeit auf, und das wird auch so bleiben.

Sagen wir es so: Die Kunst hat manche Revolution erlebt, die Kunst lebt von Abgrenzung, Ausgrenzung, Verfall, Verlust, Verwerfung - an der Büste tat sich nie viel. Anders als am innereuropäischen Schlagbaum. Sollen wir es Fortschritt nennen? Nein, Fortschritt sagen wir nicht, wenn der Zauber früher Grenzübertritte an der Mode zu Schanden wird.

Hans-Joachim Müller

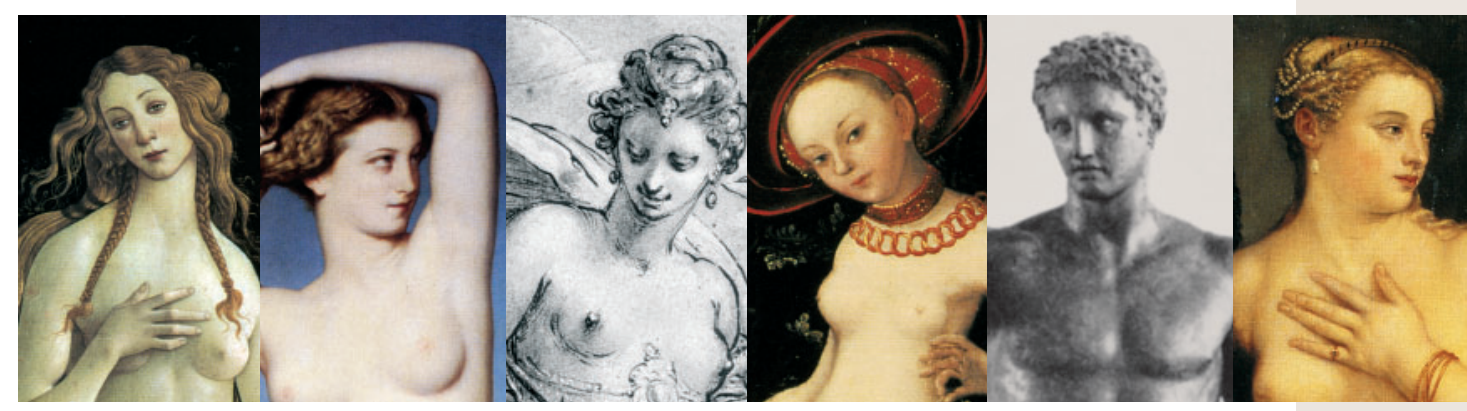

